\title{
The continuous race of therapy optimization in sepsis control
}

\author{
Doina lovănescu*, Cleo Roşculeț, Andrei Rogoz, Marius Radu, Raluca Zlotea, Cătălin Apostolescu \\ From The 10th Edition of the Scientific Days of the National Institute for Infectious Diseases "Prof Dr Matei Bals" \\ Bucharest, Romania. 15-17 October 2014
}

\section{Background}

Statistical data resulted from the analysis of the cases diagnosed and treated in the ICU of INBI Matei Bals in the last 5 years. The continuous escalation of the technical means of advanced life support associated to the antibacterial and antifungal therapy required by the proven or presumed etiology.

\section{Methods}

We analyzed risk factors, comorbidities, previous maintenance treatment schemes, a complete picture of maximal complexity which requires interdisciplinary teams.

\section{Results}

Statistical analysis of the data from the last 10 months showed a total of 186 cases of sepsis, out of which 86 cases of severe sepsis and septic shock with a very high rate of mortality (76 patients). Risk factors and comorbidities (a high rate of obesity, cardiac diseases, diabetes and immunodeficiency, elder patients $(63.6$ years old), and so on) with etiology ranging from MDR GNB (P. aeruginosa, A. baumannii, K. pneumoniae, Enterobacter spp) to gram positive cocci, $C$. difficile, fungal infections, and various viral infections (Influenza v., Parainfluenza, Enteroviruses and even Hantavirus) could explain the difficulties in the management of critically ill patients.

\section{Conclusion}

The comparative analysis with the previous years highlights the difficulties in the strategy of patient care in the ICU. Under the prescribed medication schemes there were both successes and failures, often due to the antibiotic resistance profile. The ICU cases are more and more complex, requiring the continuous optimization of the

* Correspondence: liviuiovanescu@yahoo.com

National Institute for Infectious Diseases "Prof. Dr. Matei Balş", Bucharest, Romania

C Biomed Central

(c) 2014 lovănescu et al: licensee BioMed Central Ltd. This is an Open Access article distributed under the terms of the Creative Commons Attribution License (http://creativecommons.org/licenses/by/4.0), which permits unrestricted use, distribution, and reproduction in any medium, provided the original work is properly cited. The Creative Commons Public Domain Dedication waiver (http://creativecommons.org/publicdomain/zero/1.0/) applies to the data made available in this article, unless otherwise stated. 